\title{
Living Labs as a Methodological Approach to Universal Access in Senior Design
}

\author{
Julie Christiane Thiesen Winthereik, Lone Malmborg, and Tanja Belinda Andersen
}

IT University of Copenhagen, Rued Langgaardsvej 7, 2300 Copenhagen S, Denmark

\{jctw, malmborg, tanjabelinda\} @itu.dk

\begin{abstract}
In this paper we discuss the potential of using the Living Lab methodology as an approach to ensuring universal access when designing for senior citizens. Our understanding of Living Labs is based on a recent study of 32 Living Labs cases, identifying central activities and issues in different applications of the methodology. We describe a Danish Living Lab project initiated to design for better quality of life for senior citizens in Sølund, a nursing home in Copenhagen. Two crucial concepts from the Living Lab methodology - co-creation and context - act as the core concepts for our analysis of user participation and universal access in Living Labs in general and in the Sølund Living Lab specifically. In our conclusion we suggest areas that should be given special attention when designing Living Lab projects and selecting user participants.
\end{abstract}

Keywords: Universal access, living labs, co-creation, participatory design.

\section{Introduction}

In order to design for universal access, it is crucial to reflect on the way we, as designers and researchers, represent the users that we wish to design for and consider what consequences this representation has for the given user group, which in this case is senior citizens.

The Living Lab phenomenon has its roots in very different traditions, which manifest themselves in various types of Living Labs. However these differences are rarely articulated and, despite the great interest for the Living Lab methodology, we find a profound lack of discussing the complexity of the processes and the different actors that the Living Labs involve. Central to the Living Lab thought is the user as the guarantor for successful innovation and development of the 'perfect' product that meets the actual user needs. Added to this is the idea of empowering the citizens and the communities through participation in the so-called innovation lifecycle [4].

We find there is a need for reflection on how the users are actually involved in the innovation process, how they are chosen and how this selective representation reflects back on the particular user group. Furthermore, it is our intention to deconstruct the essentialist image of user and product that is currently being reproduced in the Living Lab environment.

The article primarily finds its empirical basis in the work of Copenhagen Living Lab and their project at Sølund nursing home. We are looking at innovation of welfare technologies, which is characterized by a complex set of diverse strategies and 
values, e.g. the value of social responsibility, the strategies of political goals and agendas for re-election, the responsibility that follows with public funding etc. The complexity in this case very much has to do with the involvement of the Municipality of Copenhagen, but we still believe it is possible to draw parallels to other very different innovation syndicates, which may not be engaged in designing for senior citizens and public welfare, but still have to deal with the complexities of a user driven innovation process.

Our discussion is informed by literature on the Living Lab phenomenon, particularly the literature review made by Asbjørn Følstad [7]. We present a discussion of the concept of the users, setting out from two perspectives given by Følstad: Co-creation and context [7]. He identifies a lack of critical studies of the innovation and development processes [7, p. 120]. It is striking, though, that Følstad does not provide any new framework, but only underlines the fact that the span of Living Lab approaches is extremely wide, and that underneath the homogenizing discourse that is present in Europe exists a diverse and complex interpretation of central concepts, such as participants and context.

It is not our intention to reject the Living Lab idea as a fruitful and giving method within innovation and design, but to present a more nuanced gaze on the processes that are set in motion around the Living Lab concept and the different roles and agendas that takes place when working in a Living Lab setting. In the hype and excitement that is presently permeating the Living Lab environment, we see a risk of overlooking the complexity of the phenomenon, which could lead to failing processes and leaving the potential of the Living Lab methodology not fully tapped.

The theoretical foundation of this article and the authors themselves is grounded in anthropology and the Interaction Design tradition. This is not an anthropological study as such, but we are clearly inspired by the qualitative and hermeneutic approach that characterizes social science.

\section{Conceptual Framework of Living Labs}

Based on 32 publications on Living Labs, Følstad [7] categorizes European Living Labs in three categories: a. Living labs to experience and experiment with ubiquitous computing, b. Living Labs as open innovation platforms, and c. Living Labs exposing test bed applications to the users. He identifies main and divergent purposes, state-of-art processes and methods, and, finally, the theoretical foundations. When going through Følstad's findings, it is obvious that the different types of Living Labs have different purposes and methods, but it also becomes clear that it is not a prerequisite for Living Labs to either investigate the context of use or involve users as co-creators in any formal sense. Less than one third of the papers involve process descriptions of any forms of cocreation [7, p. 120] and the theoretical foundations described in the reviewed Living Lab articles are often rather weak or nonexistent. The theories are about co-creation and users as innovator, work from the field of Science and Technology Studies (STS) and ideas related to the field of Human-Computer Interaction [7].

Though it is not found to be the most common purposes of the living labs, the focus on context research and co-creation is, according to Følstad, the most substantial contribution to the state-of-art of Living Labs [7, p. 117]. According to Følstad's 
review there exists a general need for a thorough, but also critical, exploration of the potentials and pitfalls of user-involvement in Living Labs. This could appropriately include an exploration of the concepts of co-creation and context research. In the following we initiate such exploration by describing our case, the Sølund Living Lab.

\section{The Case: Sølund Living Lab}

The conceptual framework underlying Living Labs was discussed in the previous section. Here we present a Living Lab example from our local environment to illustrate the complexity of organization, processes and issues around a specific Living Lab case in the area of design for senior citizens.

The Sølund Living Lab is part of a project named "The Good Life of Elderly", focusing on user-centered development of the quality of life at nursing homes in Copenhagen municipality [3]. Supported by Danish research funding, the Care Department of the Municipality of Copenhagen initiated the project in autumn 2007. Project partners are from industry, rehabilitation, academic institutions and also a process facilitator (Copenhagen Living Lab - CLL). The goal is to develop solutions through innovation of new services that can make life better for elderly citizens. The Living Lab is based at the biggest nursing home in Denmark, Sølund. Staff members, residents and relatives are involved in the project. The Sølund Living Lab is situated in what Følstad would define as a "real-world context" (see section 4.2 for a more detailed discussion).

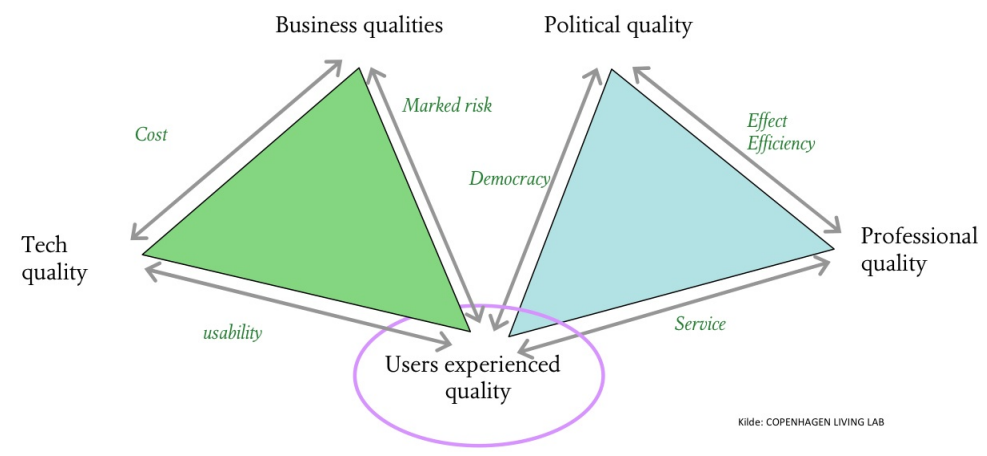

Fig. 1. Stakeholders and their relations in Sølund Living Lab [2]

In this Living Lab, the users' experiences and needs are explored and identified through ethnographic studies and qualitative analyses based on daily life practices.

\subsection{Organization}

One of the challenging issues of setting up a Living Lab is coping with multiorganizational collaboration [10] between a wide variety of stakeholders including public, industrial and academic stakeholders. Figure 1 illustrates the principles of how stakeholders in the project relate to each other. Sølund Living Lab is a construction of stakeholders from all "corners of the triangles". The right triangle represents public 
stakeholders associated with the Living Lab and the left triangle represents industrial stakeholders. This stakeholder model has been important for Copenhagen Living Lab in defining and understanding roles and power relations between stakeholders in the Sølund Living Lab initiative.

\subsection{Sølund Living Lab Life Cycle}

The life cycle maps the main activities around the Sølund Living Lab initiative. The driving force between these activities is the facilitator (CLL), but, of course, different stakeholders from the 'triangles' are involved in the activities. In the core of the life cycle is the daily life of the senior citizens.

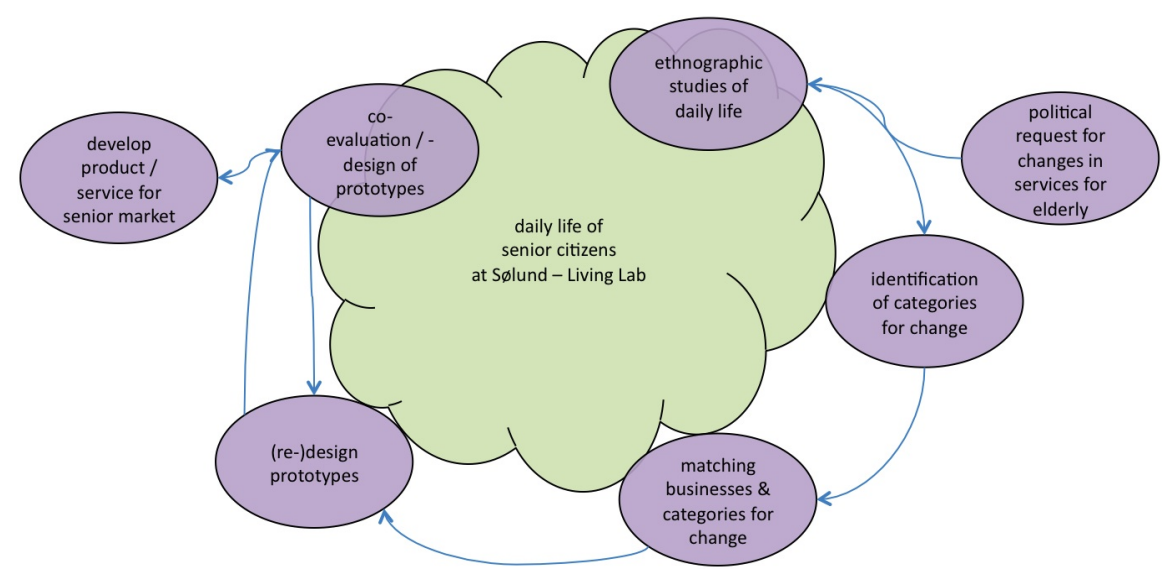

Fig 2. The Sølund Living Lab life cycle

As it becomes clear from this life cycle visualization of activities, the actual daily life of senior citizens is a central part of just two activities: the ethnographic studies of daily life and co-evaluation / -design of prototypes. If we look at the starting point and the planned ending point of the project life cycle, there is an obvious danger that the final products and services developed for the senior citizens and the senior market are not only far from the needs identified by ethnographic studies of daily life, but also far away from the original political request for change. The life cycle reveals several 'breaks', which primarily come from the fact that the seniors and their daily lives are left out of co-creation activities. The questions, that we will return to in our analysis, are by who, when and where will the interests of the residents be represented.

\section{The Challenge of Co-creation and Context}

Our analysis is divided into two parts. One part focuses on Følstad's analytical concept of co-creation and the other part on Følstad's notion of context. 


\subsection{Co-creation}

When looking into details of specific examples of living labs like the Sølund Living $\mathrm{Lab}$, we see that the concept of co-creation has many interpretations - interpretations that are probably grounded in the underlying political, ideological or philosophical paradigm of the methodological approach in the specific projects.

Theoretical foundations for co-creation in Følstad include von Hippel's [16] work on users as innovators and Scharmer's [14] work on innovation as a co-creation process involving multiple stakeholders. These conceptions and traditions of co-creation differ from the Scandinavian approach to user participation. Yngve Sundblad [15, p. 37] writes about the Scandinavian participatory design tradition that "...even at the early stages, where purpose of the design is not yet know, it is important to focus on multiple users and uses and on the experience of use. Post-design evaluation is not enough. (...) Often the problems of user participation are discussed from the point of view of researchers getting access to the users. Yet, user participation should also be seen from the point of view of the conditions of the participation process, i.e. how the conditions are set for the users to participate together with the designers." As this quote expresses it is important to clarify what the conditions for participation are. These issues of co-creation do not seem to be on the agenda in Følstad's theoretical framework, based on Scharmer and von Hippel, but they are relevant when we are analyzing how the Sølund Living Lab is organized. Følstad identifies five different activities, context research, discovery, co-creation, evaluation, and technical testing. He defines co-creation as the activity "to involve users as co-creators" [7, p. 106]. We discuss co-creation from two different perspectives. One perspective is dealing with the specific activities in which users are involved during a living lab life cycle. The second perspective regards how users are represented.

What is interesting when looking closer into the details of Følstad's activities compared with the Sølund activities is the role of technological services and products. The Sølund Living Lab process is deliberately designed in a way so that thinking in terms of new technological artifacts are not introduced to the users until very late in the process, whereas Følstad states that in many of the cases a "highly technology-driven research agenda may be the cause of the lack of activities aimed at providing general insight into end-users' context of use." [7, p. 107].

The (lack of) introduction of technological artifacts has important consequences for how co-creation takes place in the process. It seems that in most cases studied by Følstad possible technologies or services do already exist as either a concept idea or a prototype when entering the Living Lab project. This reduces the possibility of users having influence on the core idea behind the product or service.

If we look at the Discovery activity in Følstad's model, the purpose is described as gaining insight into unexpected ICT uses and new service opportunities. He mentions examples like gaining "insight through confronting (potential) users with (prototypes or demonstrators) of early technology early on in the innovation process." [7, p. 107]. He underlines that several authors do not include mechanisms for needs analysis and idea generation in their Living Lab. If we compare these two first steps with the ethnographic studies and identification of categories in the Sølund Living Lab process it is clear that the Sølund project identifies and categorizes needs among residents at the Sølund nursing home before thinking in terms of technology at all. In this way the conditions for 
user participation differ very much from the typical Living Labs in Følstad's material, where prototypes or demonstrators exist prior to the analysis of needs.

Følstad's report on co-creation activity reveals that premises or conditions for user participation in the innovation or development process are limited in most cases. $\mathrm{He}$ writes with reference to Mirijamdotter et al. [11] and Niitamo et al. [12], "In current Living Lab practices users are seen more as sources of (predefined) technology use, rather than sources of innovation." [7, p. 108]. Even if the Sølund Living Lab process leaves the initial forming of business concepts and design of prototypes with the industrial partners, these are still based on a shared understanding of the senior citizens' own experience and formulation of needs. This means that the following co-evaluation and co-design process still has this ethnographically informed material as the point of departure, whereas the typical co-creation activity reported in Følstad's study is strongly technology-driven. As an example of this Følstad mentions that Hoving [9] described the co-creative process as "being conducted through a series of action-research interventions, where end-users are provided with technology and the effects of the interventions are monitored by researchers." This is a vague and modest interpretation of co-creation compared with the Scandinavian participatory design tradition [7]. We are not able to make an analysis of the way this co-design is performed in the Sølund Living Lab as this activity is only now being planned and will take place early in autumn 2009. However, industrial partners are being invited for collaboration based on the categories for change, which in turn are based on ethnographic studies.

The issue of representation is closely related to the fundamental issue of democracy. In Pelle Ehn's early thoughts on designing for democracy at work it is stated that "the democratic ideal is a beautiful human invention, stating the right for every human to equally participate in decisions concerning his or her life. In practice, however, this freedom has always been limited." [5, p. 247]. In the participatory design tradition, with roots back to the Scandinavian tradition represented by Ehn, the selection of users to be part of the participatory design process is an issue that has received substantial attention. During the 70's and 80's when design of new information technology primarily focused on work place technologies this question was dealt with by unions. But how is this question dealt with in the Living Lab method, which always includes some selection of users, and which very often - at least in our case - deals with innovations for our homes and daily life?

In the Living Lab cases studied in Følstad the only issue brought up regarding representation is one case discussing what considerations are needed to decide the optimal number of participants in a specific Living Lab [7].

The question of representation in the Sølund case is complicated by the many stakeholders involved in the project (see figure 1). We cannot take for granted that the Municipality of Copenhagen will represent the interests of elderly, as one of the most important issues on the political agenda is how to solve the problem of the growing elderly population. This means that the perspective of the Municipality very often will be how to design and deliver more efficient services to senior citizens with fewer resources, whereas the perspective of elderly will be ensuring and enhancing their quality of life. In our interview with Thomas Hammer-Jacobsen [8] on how the Sølund Living Lab dealt with the question of representation of users' interests he said that the Copenhagen Living Lab became the ambassador for elderly by widening the scope of the Sølund Living Lab. The Municipality of Copenhagen had a narrow 
service goal focusing on how service is delivered to elderly, whereas Copenhagen Living Lab insisted that the perspective should be quality of life in a much wider sense. As a consequence of this, the selection of Living Lab participants included 7 elderly residents at Sølund, 4 care staff members at Sølund, 6 senior citizens who are preparing for their elderly life, and 6 relatives to residents at Sølund. Furthermore, CLL carefully selected participants in each of these groups on the basis of demographic variations. In this way, CLL has worked very consciously to ensure that all aspects relevant to the life of senior citizens have been explored, not just the relation between the public service provider and the residents at Sølund Living Lab.

Ensuring universal access, when using a Living Lab method, requires that the Living Lab facilitator is taking representation seriously. This means that it should be ensured that elderly and their organizations and informal ambassadors (like CLL) should have a say when participants for the Living Lab are selected. We should be aware that the public service providers have their 'efficiency'-agenda, just as the industry has their 'market'-agenda. Furthermore there is a tendency to see elderly as one single group, but the fact is that with a high number of elderly people reaching the age of 90 or 100 years, all having different experiences from long lives, they are a very varied group with many different needs that have to be considered in a design process.

\subsection{Context}

Følstad operates with three different notions of context. The first notion refers to the earlier mentioned context-research, the idea of studying the context of the users as such, for the purpose of contributions to the innovation and development process [7, p. 107]. The other two notions regard the setting of the Living Lab, namely "Familiar context" and "Real-world context". The distinction between "Familiar context" and "Real world context" is defining whether the Living Lab is set up to have the look and feel of a familiar context or if it is actually functioning in people's usual living spaces. To Følstad the familiar context setting can be seen as a threat to "ecological validity" [7, p. 110]. The idea of "ecological validity" is an interesting point to which we will return.

The process-oriented context definition "context-research" is only described and defined loosely by Følstad as research regarding context of use, including the users and their environment. Følstad argues that "context-research" is typically applied as an early research method, exactly as in the case of Sølund (as discussed in section 4.1). These context definitions that rely strongly on locality, point toward an understanding of the Living Lab as something that is both in the world and demarcated from it. This context interpretation makes it possible to believe that the wellstructured Living Lab, located in a "real-world" setting, gives the developer first hand insight into a place where the developer imagines being able to find undisturbed "ecological validity" as Følstad argues for.

But the wish and hope that follow, by which some Living Lab managers believe to be able to find answers about the "real needs", are to ignore the complex realities influencing the practical set up of the Living Lab, its innovation methods and its outcome. The discipline of social anthropology has long ago disposed the idea of any authentic unspoiled cultural settings, in which it is possible to find the definite truth about certain people and their lives. The absolute ecological valid data is thus nowhere to be found. 
The wish to overcome the problem of reductionism is exactly the common argument as to why to establish a Living Lab or other forms of "Real-World" innovation research. Researchers seek to understand and interpret lived life's complexities by looking at the users outside the usability lab - in their real life environment. However, they seem to forget that these users are not living on isolated islands and that the researchers themselves have certain perspectives with which to look. The problem of reductionism in the lab does not necessarily disappear by making a Living Lab - in practice you just install another type of lab with new forms of reductionism. We are aware that it is not possible to avoid reductionism, but it is crucial to stay reflective on the decisions made in the innovation process.

To take this argument further, we suggest an expansion, or even dissolution, of the concept of context within the Living Lab tradition. We suggest that the concept of context is re-designed to encompass what in figure 1 is called "Stakeholders and their relations". This is not so simple, both because "context" is a slippery concept and because the complexity of actors involved in doing Living Labs can be almost overwhelming, as it is revealed in figure 1. Many different stakeholders have interpreted what is good for the senior residents, but they also have their own different motives and agendas. Industry has to balance its business models towards profits, technological qualities and embedded use-qualities. Politicians have to balance the service of the citizens with resources and with upcoming elections, and care professionals have other interests, such as professional pride and values. Thus there are many diverging agendas and motives and they are negotiated in many different practices and certainly also in practices where no users are involved directly.

The discussion on context has deep roots in the social science tradition. Theoreticians have discussed at length how social scientists should encompass the "context" in research and analyses. We will not discuss such epistemological arguments at any length here, but only bring the possibly provoking standpoint - that there is no such thing as "context". By this we adopt a theoretical standpoint that seeks to overcome the split between structure, i.e. something that surrounds or frames certain practices, and situations. Instead every situation in all kind of practices must be seen as constitutive and made up by the constitutional elements present in the situation $[1, \mathrm{p}$. 71]. There exists nothing else - the situation takes place simultaneously as both agency and structure happens, which leaves no meaning left to the distinction between practice and context. The way to go is, therefore, to give attention to the different actors constituting the situations in which Living Labs happen.

It is thereby necessary to rethink the way we understand where and how the innovation processes happens. The process is going on in many practices located at different places at different times and it surely also happens many other places than in the so-called "real-life-context" of the user. In complex innovation syndicates, such as the Sølund case, but also in all other Living Lab setups, much of the innovation process is happening far away from the user.

In Sølund, the goals of innovating for elderly residents are compromised in the process of innovation where, as we discussed in 4.1, the life cycle of the innovation process "forgets" to integrate the "users" all the way. There can be very good reasons for this and Thomas Hammer-Jacobsen agrees that in the innovation process there "is a lot in play that does not have anything to do with the quality of life for old people" [8]. The challenge is to be aware of how such diverging agendas are reflected in the 
decisions and thereby the outcome of the Living Lab activities; in practices directly involving co-construction activities as well as in other practices that do not directly involve users. The massive influence of various actors is thus embedded in many practices regarding the living lab life cycle in an ongoing changeable process. This does not leave room for findings of "real needs" or ecological valid data. A successful Living Lab is consequently not a simple question of the right set up; the complexity is universal, if nothing else is!

\section{Conclusion}

Through our analysis of the concepts of co-creation and context in the Living Lab literature and in the Sølund case, we have revealed crucial methodological issues when applying the method in the field of design for seniors. Ensuring universal access through user participation, when designing services and technologies for senior citizens, requires special attention on how this user group and its life situation is represented in the Living Lab setting.

Regarding representation in a co-creation process, it is important to take into account in which way, and by whom, the users are represented throughout the living lab life cycle. Seniors should not be considered as one homogeneous group. The various needs and life situations that exist among different groups of senior citizens should be taken into account along with decisions regarding delimitation of participants.

Regarding context, we consider the most important issue to be awareness of different conceptions of context and how to avoid unreflected reductionism. Many different stakeholders have interpretations of what is best for the senior citizens, but they also have different motives and agendas. Thus context should be understood in the complex landscape of stakeholders, their mutual relations and conflicting agendas.

We do not consider Living Labs a failed methodology, but we advocate for both academia and industry to bear in mind that no methodology or type of research is ever neutral, but is always a result of choice and ideological perspectives. It is such choices and ideologies that we, as researchers and product designers, should always be conscious about.

\section{References}

1. Clarke, A.E.: Situational Analysis - Grounded Theory After the Postmodern Turn. SAGE Publications, Inc., Thousand Oaks (2005)

2. Copenhagen Living Lab: Finding the positional match. Unpublished document (2009)

3. Copenhagen Living Lab: Det gode ældreliv - 8 innovationsspor, arbejdshæfte (2008)

4. Directorate-General for the Information Society and Media: Living Labs for User-driven Open Innovation - An Overview of the Living Labs Methodology, Activities and Achievements (2009),

http://ec.europa.eu/information_society/activities/

livinglabs/docs/brochure_jan09_en.pdf

5. Ehn, P.: Work-Oriented Design of Computer Artifacts. Swedish Center for Working Life (1988) 
6. Erhvervs- og byggestyrelsen: Det gode ældreliv (2006), http: / /www. ebst.dk/brugerdreveninnovation.dk/aeldreliv

7. Følstad, A.: Living Labs for Innovation and Development of Information and Communication Technology: A Literature Review. eJOV 10 (2008)

8. Hammer-Jacobsen, T.: Interview with Thomas Hammer-Jacobsen about Copenhagen Living Lab and the Sølund case (2009)

9. Hoving, D.: Enhancing the quality of life in a living lab Moerwijk (The Hague), The New Media (2003)

10. Kviselius, N.Z., Ozan, H., Edenius, M., Andersson, P.: The Evolution of Living Labs Propositions for Improved Design and Further Research. In: The 5th International Conference on Innovation and Management (ICIM 2008), aastricht, the Netherlands, December 10-11 (2008)

11. Mirijamdotter, A., Ståhlbröst, A., Sällström, A., Niitamo, V.-P., Kulkki, S.: The European Network of Living Labs for CWE - user-centric co-creation and innovation. In: EChallenges 2006, Barcelona, Spain, October 25-27 (2006)

12. Niitamo, V.-P., Kulkki, S., Eriksson, M., Hribernik, K.A.: State-of-the-art and good practice in the field of living labs. In: The 12th International Conference on Concurrent Enterprising: Innovative Products and Services through Collaborative Networks, ICE 2006, Milan, Italy, June 26-28, pp. 349-357 (2006)

13. Pedersen, J.: Protocols of Participatory Design and Workplace Studies, ITU (2007)

14. Scharmer, O.: Theory U: Leading From the Future as it Emerges. Sol, Cambridge (2007)

15. Sundblad, Y.: From Utopia 1981 to Utopia 2008. In: Binder, L., Malmborg (eds.) (Re)Searching the Digital Bauhaus. Springer, Heidelberg (2009)

16. Von Hippel, E.: The Sources of Innovation. Oxford University Press, New York (1988) 